Sussex home - the recent purchase of an adjoining field had allowed him to develop a nature reserve with meadow, hedgerows and trees chosen to fit the habitat - with exacting attention to detail.

Throughout his working life he was supported by his wife. Evelyn, who survives him; his two sons, Robert and Matthew, both doctors; and his daughter. Frances, a journalist. Six grandchildren, of whom he was intensely proud, added to the joy of his retirement. That, "damp February morning with nothing to do" never came.

MATTHEW S. STEAD

\title{
Corrigendum
}

\section{Negative marking in the MRCPsych Examination}

Cormac \& Marston (Psychiatric Bulletin. March 1999, 23, 172-176) have provided a useful guide to those taking the MRCPsych Examinations. However, there has been a change in the Examination Regulations since they wrote their article. On the advice of a medical educationalist, who has been assisting the Examinations Department, negative marking in the Multiple Choice Question papers is being discontinued. In the Spring 1999 Examinations only correct replies to multiple choice questions will be scored; those questions that are answered incorrectly or omitted will receive the same zero mark. This change will apply in both the Part I and Part II MCQ papers.

All candidates and Tutors involved in the forthcoming Examination have been informed of this change, but I would like to highlight this in order to avoid any misunderstanding.

Stephen Tyrer, Chief Examiner, Royal College of Psychiatrists, 17 Belgrave Square, London SWIX 8PG 